\title{
FITOTECNIA
}

\section{EFEITO DA ÉPOCA DE COLHEITA NO CRESCIMENTO VEGETATIVO, NA PRODUTIVIDADE E NA QUALIDADE DE RAÍZES DE TRÊS CULTIVARES DE MANDIOCA ${ }^{(1)}$}

\author{
EDVALDO SAGRILO(2); PEDRO SOARES VIDIGAL-FILHO ${ }^{(3,5)}$; \\ MANOEL GENILDO PEQUENO ${ }^{(4,6)}$; CARLOS ALBERTO SCAPIM ${ }^{(3)}$; \\ MARIA CELESTE GONÇALVES-VIDIGAL ${ }^{(3)}$; ROGÉRIO RUI MAIA ${ }^{(4)}$; \\ MARCUS VINÍCIUS KVITSCHAL ${ }^{(4)}$
}

\begin{abstract}
RESUMO
Com o objetivo de determinar o efeito da época de colheita no crescimento vegetativo, na produtividade e na qualidade de raízes tuberosas de três cultivares de mandioca (Manihot esculenta Crantz), desenvolveu-se em Araruna, Noroeste do Estado do Paraná, um experimento em área de Latossolo Vermelho Distrófico, no período de outubro de 1997 a maio de 1999. O delineamento experimental utilizado foi o de blocos completos casualizados, em esquema de parcelas subdivididas, com quatro repetições, sendo os tratamentos principais as cultivares Mico, IAC 13 e IAC 14 e os tratamentos secundários, dez épocas de colheita, realizadas mensalmente a partir do início do segundo ciclo de crescimento das plantas. A produção da parte aérea apresentou, no segundo ciclo, aumentos de 50,0\% em relação a um único ciclo vegetativo. $\mathrm{O}$ bom desenvolvimento da estrutura vegetativa das plantas levou ao acúmulo de material de reserva nas raízes tuberosas, aumentando a sua produtividade. Os maiores índices de colheita ocorreram dos 19 aos 21 meses de idade, com valores, em média, superiores a 54,0\%. As cultivares não diferiram entre si quanto à produção de raízes tuberosas, de massa seca e de amido. Para todas as cultivares, a segunda fase de repouso fisiológico das plantas mostrou-se mais propícia à colheita, em face da maior produção de raízes tuberosas $(92,5 \%)$, de massa seca $(125,0 \%)$ e de amido $(144,0 \%)$.

Palavras-chave: parte aérea, índice de colheita, produção de raízes, produção de amido, idade das plantas.
\end{abstract}

\section{ABSTRACT}

\section{EFFECT OF THE HARVESTING TIME IN THE VEGETATIVE GROWTH, YIELD AND QUALITY OF THE STORAGE ROOTS OF THREE CASSAVA CULTIVARS}

With the objective of determining the effect of harvesting time in the vegetative growth, yield and quality of storage roots of three cassava cultivars (Manihot esculenta Crantz), an experiment was carried out in an area of red distrophic Red Latosol in Araruna, Northwest of Paraná state, from October, 1997 to May, 1999. The experimental design was a randomized complete blocks with four replications and treatments arranged in split plots. The main treatments were the cassava cultivars Mico, IAC 13 and IAC 14 and the secondary treatments were ten monthly harvests starting from the second plant growing season. The canopy yield observed in the second season, presented an increase of $50.0 \%$. The good development of the vegetative structure of the plants resulted in a greater accumulation of reserve material in the storage roots, increasing its yield. The highest harvest indices were observed from 19 to 21 months, with mean values superior to $54.0 \%$. The cultivars were not significantly different in production of tuberous roots, dry matter and starch. The second phase of physiologic rest of the plants showed to be more favourable for harvesting, expressed in terms of production of storage roots $(92.5 \%)$, of dry matter $(125.0 \%)$ and starch $(144.0 \%)$.

Key words: canopy, harvest index, root production, starch production, age of plants.

${ }^{1}$ ) Parte da dissertação de Mestrado do primeiro autor, apresentada ao Programa de Pós-Graduação em Agronomia, Universidade Estadual de Maringá (UEM). Recebido para publicação em 29 de junho de 2001 e aceito em 20 de maio de 2002.

$\left({ }^{2}\right)$ Centro de Pesquisa Agropecuária do Meio-Norte - Embrapa Meio-Norte (CPAMN). Avenida Duque de Caxias, 5650, 64006-220 Teresina (PI). E-mail: sagrilo@cpamn.embrapa.br

$\left({ }^{3}\right)$ Departamento de Agronomia, UEM. Av. Colombo 5790, 87020-900 Maringá (PR). E-mail: gvidigal@wnet.com.br

$\left({ }^{4}\right)$ Aluno de Pós-Graduação em Agronomia da Universidade Estadual de Maringá, UEM. E-mail: mvk78@hotmail.com

(5) EMATER. Escritório Regional de Campo Mourão, 87300-030 Campo Mourão (PR). E-mail: magepe@uol.com.br

$\left({ }^{6}\right)$ Com bolsa de produtividade científica do CNPq. 


\section{INTRODUÇÃO}

A mandioca (Manihot esculenta Crantz) caracteriza-se por ser uma planta tolerante a condições de seca e baixa fertilidade do solo, sendo este o principal motivo pelo qual é comumente cultivada e consumida por pequenos produtores rurais em áreas com solos pobres, e onde as condições climáticas são constantemente desfavoráveis à exploração de outras culturas. Entretanto, a mandioca constitui-se como a base alimentar para aproximadamente 500 milhões de pessoas no mundo todo (CASSAVA, 2000), além de ser utilizada no arraçoamento animal e como matéria-prima para diversos produtos agroindustrializados (DORETTO, 1993).

O Estado do Paraná, com uma área de cultivo de 192 mil hectares e um volume de 3,9 milhões de toneladas de raízes tuberosas produzidas na safra 1999/2000, é um dos principais Estados produtores do Brasil, com produtividade média de 20,47 t.ha ${ }^{-1}$ (GRохко, 2000). Embora bastante superior à média nacional, de 13,85 Mg.ha-1 (IвGE, 2000), encontra-se, ainda, aquém daquela possível de se obter, atribuindo-se as baixas produtividades ao uso de cultivares e às épocas de colheita inadequados (Fukuda e CAldas, 1985). Dessa forma, tem-se relacionado a melhor época de colheita, entre outros fatores, às condições edafoclimáticas do meio ambiente e à cultivar, definidas em pesquisas, em que se avaliam a produtividade de raízes tuberosas, bem como os teores de massa seca e de amido (SARMENTO, 1997).

Estudos desenvolvidos por PaUla (1976), em Viçosa-MG, permitiram concluir que cultivares com dois ciclos vegetativos apresentam maiores produções de raízes tuberosas, quando comparadas com os cultivos com apenas um ciclo vegetativo. De forma análoga, segundo CoNCEIÇão (1981), há quem afirme que a produção de uma cultura de mandioca com dois ciclos vegetativos seja, em média, 80,0\% superior à produção da mesma cultura com apenas um ciclo vegetativo, recomendando a colheita para uso agroindustrial no segundo ciclo porque tanto a produção de raízes tuberosas como também a de amido são maiores. Por sua vez, FuKUdA e CALDAS (1985) observaram que algumas cultivares dobraram sua capacidade produtiva quando a época de colheita foi ampliada de 12 para 18 meses.

Avaliando a produtividade e a qualidade de raízes tuberosas de mandioca em diferentes épocas de colheita em Lavras (MG), CARVALHO et al. (1993) também encontraram diferenças entre cultivares quanto à idade de maior produção de raízes tuberosas, a qual ocorreu aos 16 meses para a cultivar Iracema, aos 20 meses para Mantiqueira e Brancade-Santa Catarina e aos 22 meses para Sonora, Engana Ladrão e Guaxupé. Segundo esses autores, todas as cultivares apresentaram, aos 20 meses após o plantio, elevada produtividade de raízes tuberosas, com elevados teores de massa seca e de amido, ressaltando que tal coincidência é fator desejável, pois se terá maior rendimento agrícola e industrial (farinha e fécula).

Assim, a introdução de cultivares para uso agroindustrial em determinada região deve, segundo LEONEL-NETO (1983), ser precedida do conhecimento do seu comportamento diante das condições locais, sobretudo em função da época de colheita, visto que o desconhecimento do comportamento das cultivares em relação à época de colheita pode, muitas vezes, levar o produtor a colher a mandioca em períodos desfavoráveis (CORRÊA e ROCHA, 1979).

Por esse motivo, o presente trabalho teve como objetivo determinar o efeito da época de colheita no crescimento vegetativo, na produtividade e na qualidade de raízes tuberosas de três cultivares de mandioca durante o segundo ciclo vegetativo, em Araruna, Região Noroeste do Estado do Paraná.

\section{MATERIAL E MÉTODOS}

O experimento foi desenvolvido de outubro de 1997 a maio de 1999, no município de Araruna (PR), em área de Latossolo Vermelho Distrófico (EMBRAPA, 1999), pertencente à PINDUCA - Indústria Alimentícia Ltda. O município de Araruna encontrase situado a $23^{\circ} 55^{\prime}$ de Latitude Sul e a $52^{\circ} 30^{\prime}$ de longitude Oeste de Greenwich, com altitude média de $660 \mathrm{~m}$. O solo, de acordo com a análise química de amostras da área experimental, na camada de 0,0$0,20 \mathrm{~m}$, efetuada antes da implantação do experimento, apresentou a seguinte composição: $\mathrm{pH}$ $\left(\mathrm{CaCl}_{2}\right)$ 5,2; $\mathrm{pH}$ (água) 6,4; $\mathrm{Al}^{3+}\left(\mathrm{cmol}_{\mathrm{c}} \cdot \mathrm{dm}^{-3}\right)$ 0,00; $\mathrm{H}^{+}$ $+\mathrm{Al}^{3+}\left(\mathrm{cmol} \cdot \mathrm{dm}^{-3}\right) 3,17 ; \mathrm{Ca}^{2+}+\mathrm{Mg}^{2+}\left(\mathrm{cmol} \cdot \mathrm{dm}^{-3}\right)$ 2,44; $\mathrm{Ca}^{2+}\left(\mathrm{cmol}_{c} \cdot \mathrm{dm}^{-3}\right) 1,49 ; \mathrm{K}^{+}\left(\mathrm{cmol}_{c} \cdot \mathrm{dm}^{-3}\right)$ 0,32; $\stackrel{\mathrm{P}}{\mathrm{C}}\left(\mathrm{mg} \cdot \mathrm{dm}^{-3}\right)$ 5,0 e C (g.dm $\left.{ }^{-3}\right) 13,57$. O clima de Araruna, segundo Köppen, pertence ao tipo $\mathrm{Cfb}$, com temperatura média anual de $21,5^{\circ} \mathrm{C}$, precipitação média anual de $1.617 \mathrm{~mm}$ e umidade relativa média anual de $62,0 \%$ (Godor et al., 1976). Os dados climáticos registrados no período experimental encontram-se na figura 1.

Os tratamentos utilizados no presente trabalho constaram de três cultivares de mandioca, colhidas em dez épocas durante o segundo ciclo vegetativo, a partir do $12 .^{\circ}$ mês após o plantio. As cultivares, definidas com base em resultados experimentais 


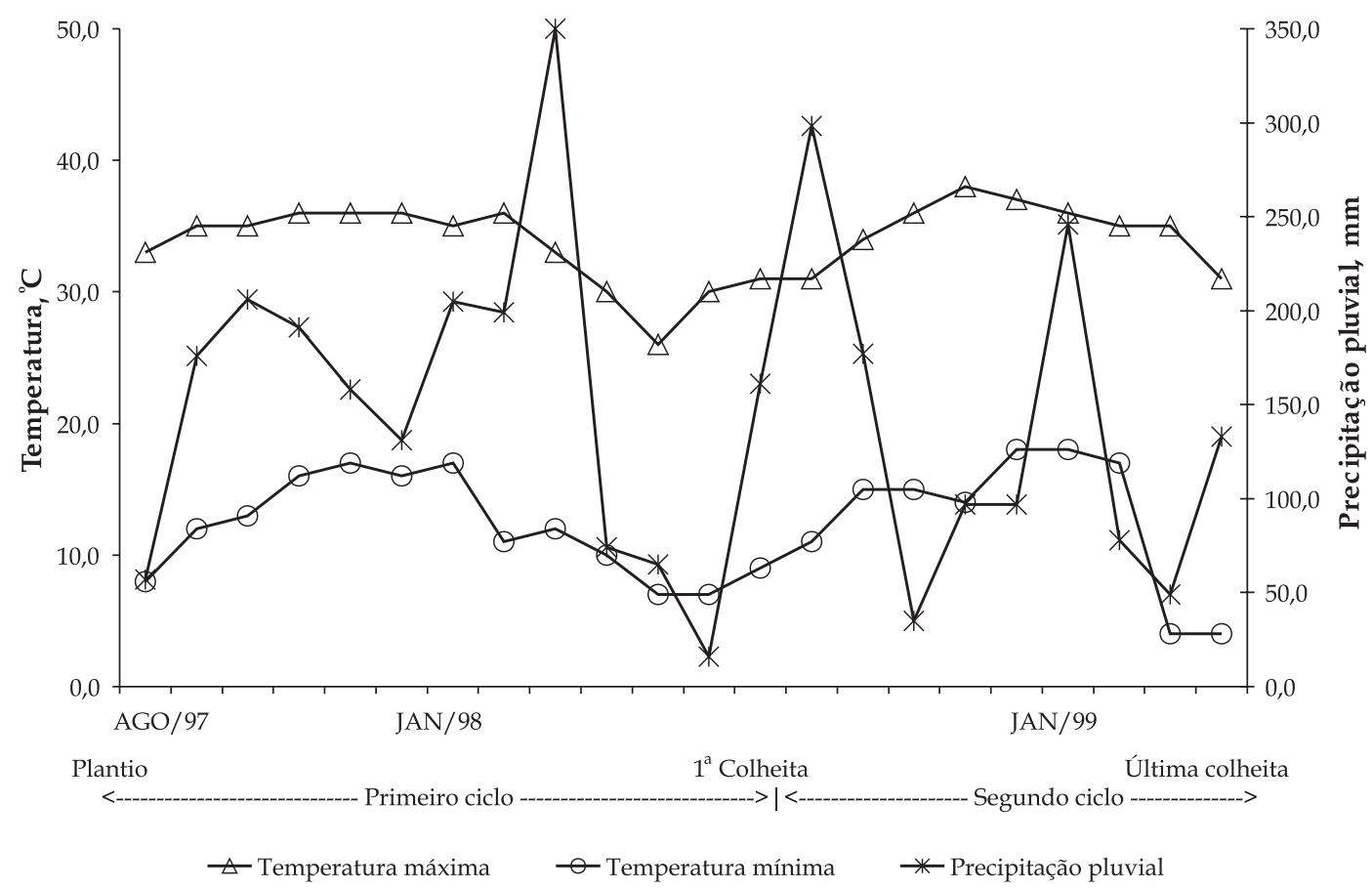

Figura 1. Valores médios mensais de precipitação pluvial e temperaturas máximas e mínimas observadas no período de agosto de 1997 a maio de 1999, em Araruna (PR).

obtidos no período de 1994 a 1997 e publicados por VIDIGAL-FILHO et al. (2000), foram Mico, IAC 13 e IAC 14 , todas consideradas aptas para cultivo na região. O delineamento experimental utilizado foi o de blocos completos casualizados, em esquema de parcelas subdivididas, com quatro repetições, sendo dispostas nas parcelas as cultivares (tratamentos principais) e nas subparcelas, casualizadas dentro de cada bloco, as épocas de colheita (tratamentos secundários).

As parcelas apresentaram dimensões de $17,6 \mathrm{~m}$ de comprimento por $22,0 \mathrm{~m}$ de largura, com espaçamento de 1,0 m entre fileiras e $0,80 \mathrm{~m}$ entre plantas de uma mesma fileira. Cada parcela apresentou área total de $387,2 \mathrm{~m}^{2}$, contando com 10 subdivisões, cada qual referente a uma época de colheita (subparcelas), composta por uma fileira de 22 plantas, com bordaduras laterais individuais intercaladas entre si; descartaram-se as plantas das extremidades de cada subparcela (bordaduras de cabeceira). A área útil de cada subparcela foi de $16,0 \mathrm{~m}^{2}$, composta por 20 plantas que foram colhidas e avaliadas. A seleção e o preparo do material de plantio, bem como os tratos culturais realizados durante o período experimental, foram aqueles comuns à cultura da mandioca, conforme recomendações de ConCEIçño (1981) e LORENZI e DiAs (1993).

Das plantas colhidas, tomaram-se amostras de raízes tuberosas com massa conhecida $(0,06 \mathrm{~kg})$, as quais foram fatiadas e cortadas em cubos aproximadamente de $0,01 \mathrm{~m}$ de aresta e secas em estufa de circulação forçada de ar a $60^{\circ} \mathrm{C}$ (SALEs-FILHO, 1980), para determinar o teor de massa seca e o teor de amido e, posteriormente, sua produção por área $\left(\mathrm{Mg} \cdot \mathrm{ha}^{-1}\right)$. Após pesagem, os cubinhos de raízes tuberosas foram triturados em moinho do tipo WileyThomas, com peneira de aço inoxidável 60 mesh e acondicionados em tubos de Wheaton até o momento das análises. Avaliaram-se as seguintes características:

Produção da parte aérea (PPA): valor médio expresso em Mg.ha- ${ }^{-1}$, obtido pela pesagem da parte aérea das plantas, a partir do corte realizado a 0,10 $\mathrm{m}$ da superfície do solo, em todas as plantas da área útil de cada subparcela;

Produção de raízes tuberosas (PRODR): valor médio expresso em Mg.ha ${ }^{-1}$, obtido pela pesagem das raízes tuberosas de todas as plantas da área útil de cada subparcela;

Índice de colheita (IC): valor médio expresso em porcentagem (\%), obtido pela seguinte relação:

$$
\mathrm{IC}=\frac{\mathrm{PRODR}}{\mathrm{PRODR}+\mathrm{PPA}} \times 100
$$

em que PRODR é a produção de raízes tuberosas $\left(\mathrm{Mg} \cdot \mathrm{ha}^{-1}\right)$ e PPA, a produção da parte aérea $\left(\mathrm{Mg} \cdot \mathrm{ha}^{-1}\right)$. 
Produção de massa seca de raízes tuberosas (PRMS): valor médio expresso em Mg.ha- ${ }^{-1}$, obtido pela relação a seguir:

$$
\mathrm{PRMS}=\frac{\mathrm{PRODR} \times \mathrm{MSR}}{1000}
$$

em que PRODR é a produção de raízes tuberosas $\left(\mathrm{Mg} \mathrm{ha}^{-1}\right)$ e MSR, o teor de massa seca nas raízes tuberosas $\left(\mathrm{g} \cdot \mathrm{kg}^{-1}\right)$.

Produção de amido (PRAM): valor médio expresso em t.ha ${ }^{-1}$, obtido pela relação:

$$
\mathrm{PRAM}=\frac{\mathrm{PRODR} \times \mathrm{AMF}}{1000}
$$

em que PRODR é a produção de raízes tuberosas $\left(\mathrm{Mg} \cdot \mathrm{ha}^{-1}\right)$ e AMF, o teor de amido na massa fresca das raízes tuberosas $\left(\mathrm{g} . \mathrm{kg}^{-1}\right)$, determinado pelo método do Iodo (método clássico; DiNIZ, 1999).

Os dados obtidos foram submetidos à análise da variância convencional para os efeitos principais (cultivares e épocas de colheita), bem como para sua interação (cultivar x época de colheita). Quando da interação significativa, procedeu-se aos desdobramentos necessários, conforme recomendações de BANZATto e KRONKA (1995). As médias das cultivares foram comparadas entre si, pelo teste de Tukey a $5 \%$ de probabilidade, enquanto as médias das épocas de colheita, analisadas, quando possível, por meio de modelos de equações de regressão polinomial.

Para a característica produção de raízes tuberosas, utilizou-se um modelo logístico de quatro parâmetros, qual seja, $\mathrm{y}=\mathrm{a}+\mathrm{b} /((1+\exp (-(\mathrm{x}-\mathrm{c})$ / d )), cujos parâmetros são descritos da seguinte forma: o parâmetro " $a$ " corresponde à assíntota mínima; o parâmetro " $b$ ", à diferença entre a assíntota máxima e a assíntota mínima; o parâmetro " $c$ ", ao ponto de inflexão da curva, e o parâmetro " $\mathrm{d}$ " descreve o declive da curva (RATKOWSKY, 1990).

\section{RESULTADOS E DISCUSSÃO}

Observa-se, pelo quadro 1, que para todas as características avaliadas, houve efeito significativo $(\mathrm{P} \leq 0,05)$ de épocas de colheita. Observou-se, também, significância estatística do fator cultivar para as características produção da parte aérea e índice de colheita, sendo, entretanto, não significativo para as características: produção de raízes tuberosas, produção de massa seca e produção de amido de raízes tuberosas. Por sua vez, a interação entre cultivares $x$ épocas de colheita mostrou efeito não significativo para todas as características avaliadas, para as quais se encontram representados graficamente os dados oriundos da média das cultivares avaliadas.

\subsection{Produção da parte aérea total}

Observa-se que nas três primeiras colheitas, realizadas dos 12 aos 14 meses, as médias de produção da parte aérea total permaneceram constantes, aumentando a partir deste período até os 17 meses após o plantio, sofrendo nova redução até os 19 meses e estabilizando-se nas três colheitas finais, com valores aproximadamente 50,0\% superiores ao observado no início do período de colheitas (Figura 2).

Constatou-se que a produção da parte aérea dependeu, sobretudo, de fatores de ordem climática, e o aumento mais pronunciado das médias, observado dos 14 aos 17 meses de idade (outubro a janeiro), foi conseqüência não só do aumento na produção de hastes, mas também da produção de folhas, as quais foram favorecidas pela elevada temperatura e pelo aumento da precipitação pluvial neste período (Figura 1). De acordo com MonTALDO (1979), durante os meses quentes e úmidos, as plantas vegetam de modo abundante, sendo o posterior decréscimo na produção da parte aérea resultado da queda das folhas, fenômeno natural e normal, condicionado pela redução da temperatura e pela escassez de água disponível (Figura 1), conforme HAMmer et al. (1987) e Hobman et al. (1987).

Variações na produção da parte aérea em razão da época de colheita foram também relatadas por LeONEL-Neto (1983), que encontraram maiores valores em períodos de desenvolvimento vegetativo, durante o ciclo cultural, condicionado pelas variações climáticas. A regeneração da estrutura vegetativa na estação de crescimento é comumente observada na mandioca (HAMmer et al., 1987), embora alguns autores tenham relatado não ter havido influência significativa da época de colheita no comportamento de cultivares de mandioca, quanto à produção da parte aérea (FuKUDA e CALDAS, 1985).

As cultivares avaliadas neste estudo mostraram diferenças significativas no que se refere à produção da parte aérea. Observa-se, no quadro 2, que a cultivar IAC 14 apresentou as maiores médias para esta característica, seguida da cultivar Mico e da cultivar IAC 13. Esses dados estão de acordo com resultados obtidos em estudos prévios realizados no 
Quadro 1. Análise da variância (Quadrados médios) dos dados referentes à produção da parte aérea, produção de raízes tuberosas, índice de colheita, produção de massa seca e produção de amido de três cultivares de mandioca em dez épocas de colheita durante o segundo ciclo vegetativo. Araruna (PR), 2001

\begin{tabular}{|c|c|c|c|c|c|c|}
\hline Fontes de variação & GL & $\begin{array}{c}\text { Produção da } \\
\text { parte aérea }\end{array}$ & $\begin{array}{c}\text { Produção de } \\
\text { raízes tuberosas }\end{array}$ & $\begin{array}{l}\text { Índice de } \\
\text { colheita }\end{array}$ & $\begin{array}{c}\text { Produção de } \\
\text { massa seca }\end{array}$ & $\begin{array}{l}\text { Produção } \\
\text { de amido }\end{array}$ \\
\hline & & \multicolumn{2}{|c|}{$\longrightarrow$ Mg.ha ${ }^{-1} \longrightarrow$} & $\%$ & \multicolumn{2}{|c|}{ Mg.ha-1 } \\
\hline Blocos & 3 & 24,77 & 107,86 & 154,89 & 12,22 & 7,08 \\
\hline Cultivares (C) & 2 & $1.471,51^{*}$ & $87,66^{\mathrm{ns}}$ & $895,88^{*}$ & $20,53 \mathrm{~ns}$ & $3,29^{\mathrm{ns}}$ \\
\hline Resíduo (a) & 6 & 85,41 & 90,37 & 122,57 & 10,64 & 5,21 \\
\hline Épocas de colheitas (E) & 9 & $329,27^{*}$ & $669,11^{*}$ & $205,13^{*}$ & $126,53^{*}$ & $82,57^{*}$ \\
\hline $\mathrm{C} \times \mathrm{E}$ & 18 & $59,20^{\mathrm{ns}}$ & $22,75^{\mathrm{ns}}$ & $10,23^{\text {ns }}$ & $3,15^{\mathrm{ns}}$ & $1,71^{\mathrm{ns}}$ \\
\hline Resíduo (b) & 81 & 34,67 & 19,85 & 15,01 & 3,07 & 1,49 \\
\hline CV da parcela (\%) & & 34,42 & 35,69 & 22,49 & 34,95 & 38,96 \\
\hline CV da subparcela (\%) & & 21,93 & 16,73 & 7,87 & 18,76 & 20,83 \\
\hline Média geral & & 26,85 & 26,64 & 49,22 & 9,33 & 5,86 \\
\hline
\end{tabular}

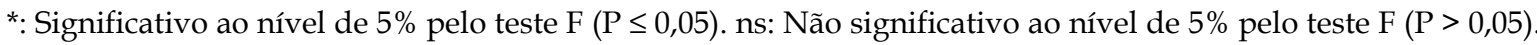

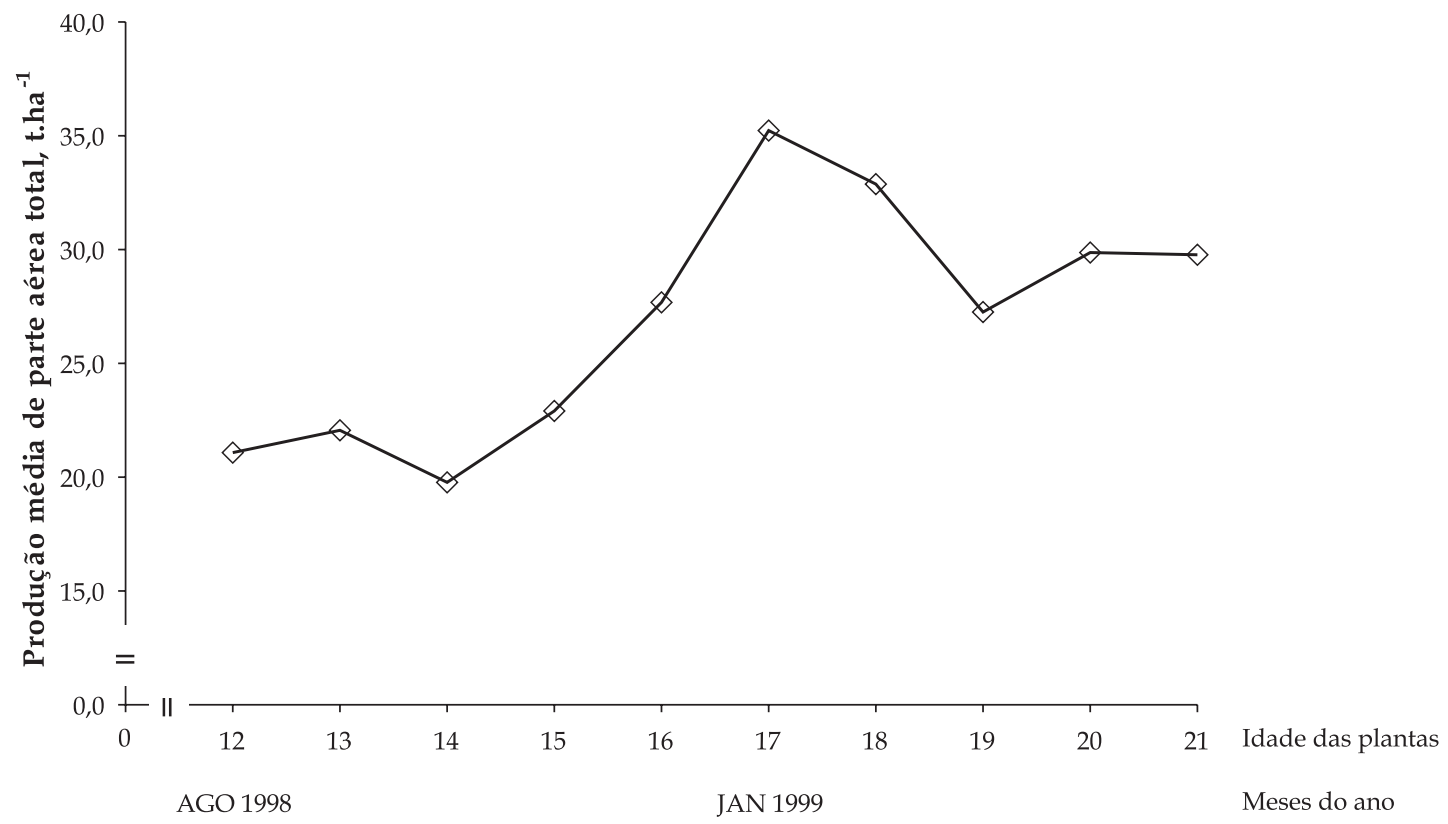

Figura 2. Variação na produção média de parte aérea $\left(\mathrm{Mg}_{\text {.ha }}{ }^{-1}\right)$ de três cultivares de mandioca em dez épocas de colheita, durante o segundo ciclo vegetativo. Araruna (PR), 2001.

período de 1994 a 1997 por ViDigAL-FiLHO et al. (2000), que encontraram maiores produções da parte aérea total com a cultivar IAC 14, ao avaliar plantas de nove cultivares de mandioca em um ciclo vegetativo. As diferenças existentes quanto à produção da parte aérea parecem estar condicionadas à constituição genética inerente a cada cultivar, além de sofrerem influência de fatores ambientais, conforme relatam LORENZI et al. (1988).

\subsection{Produção de raízes tuberosas}

Os resultados obtidos ao longo de dez épocas de colheita, a partir do início do segundo ciclo vegetativo (12 meses após o plantio), mostraram que as médias permaneceram inalteradas dos 12 aos 15 meses (agosto a novembro), caracterizando um platô inicial com a produtividade estabilizada em torno de 19,3 Mg.ha-1. A partir dos 15 meses, ocorreu um aumento 
bastante rápido da produção de raízes tuberosas, persistindo até os 19 meses (março), atingindo um novo platô, que se seguiu até os 21 meses de idade (maio), com os valores praticamente inalterados, próximos de 35,8 Mg.ha-1 (Figura 3).

O comportamento sigmóide observado para essa característica (Figura 3) caracterizou-se por uma alternância entre períodos de intensa atividade fisiológica e períodos de repouso da planta, os quais foram condicionados, sobretudo, pelas condições climáticas prevalecentes. Assim, o período compreendido entre os 12 e os 15 meses marcou o final da primeira fase de repouso vegetativo e o início da nova estação de crescimento.

Com o restabelecimento do regime de chuvas e o aumento da temperatura média observada após os 15 meses (Figura 1), as plantas, já no segundo ciclo vegetativo, retomaram o crescimento, o que resultou na elevação da atividade fotossintética e, conseqüentemente, no aumento da produção de raízes tuberosas.

O novo platô que se seguiu a partir dos 19 meses (março) ocorreu por ocasião da aproximação do início do segundo período de repouso fisiológico das plantas, o qual foi condicionado mais uma vez pela redução da taxa de precipitação pluvial e pela queda da temperatura (Figura 1). Por sua vez, trabalhos desenvolvidos por SRIROTH et al. (1999), na Tailândia, mostraram que a produção de raízes tuberosas cresceu continuamente com o aumento da idade das plantas, sem mencionarem a distinção entre períodos de baixa e de elevada produção de raízes tuberosas. De forma análoga, KAYODE (1983) afirmou que as raízes tuberosas de mandioca aumentaram seu tamanho continuamente e, conseqüentemente, sua produção, quando as mantiveram por longos períodos no campo.

As médias estimadas, obtidas no fim do período de colheitas, foram $92,5 \%$ superiores àquelas observadas no início das colheitas, aumento semelhante verificado por HAMMER et al. (1987). Segundo esses autores, em locais onde o teor de umidade no solo não representa perigo ao apodrecimento das raízes tuberosas, a cultura da mandioca pode ser colhida no segundo ano, pois a produtividade nesse período comumente apresenta aumento até de 100,0\%.

Com relação às cultivares (Quadro 2), observa-se que não houve diferença significativa entre as médias comparadas $(\mathrm{P}>0,05)$, quanto à produção de raízes tuberosas. Por sua vez, Vidigal-Filho et al. (2000), estudando plantas com um ciclo vegetativo, obtiveram em geral, maior produtividade com as cultivares Fécula Branca, Fibra, Espeto, Verdinha e Mico, quando comparadas com 'IAC 13' e 'IAC 14', entre outras.

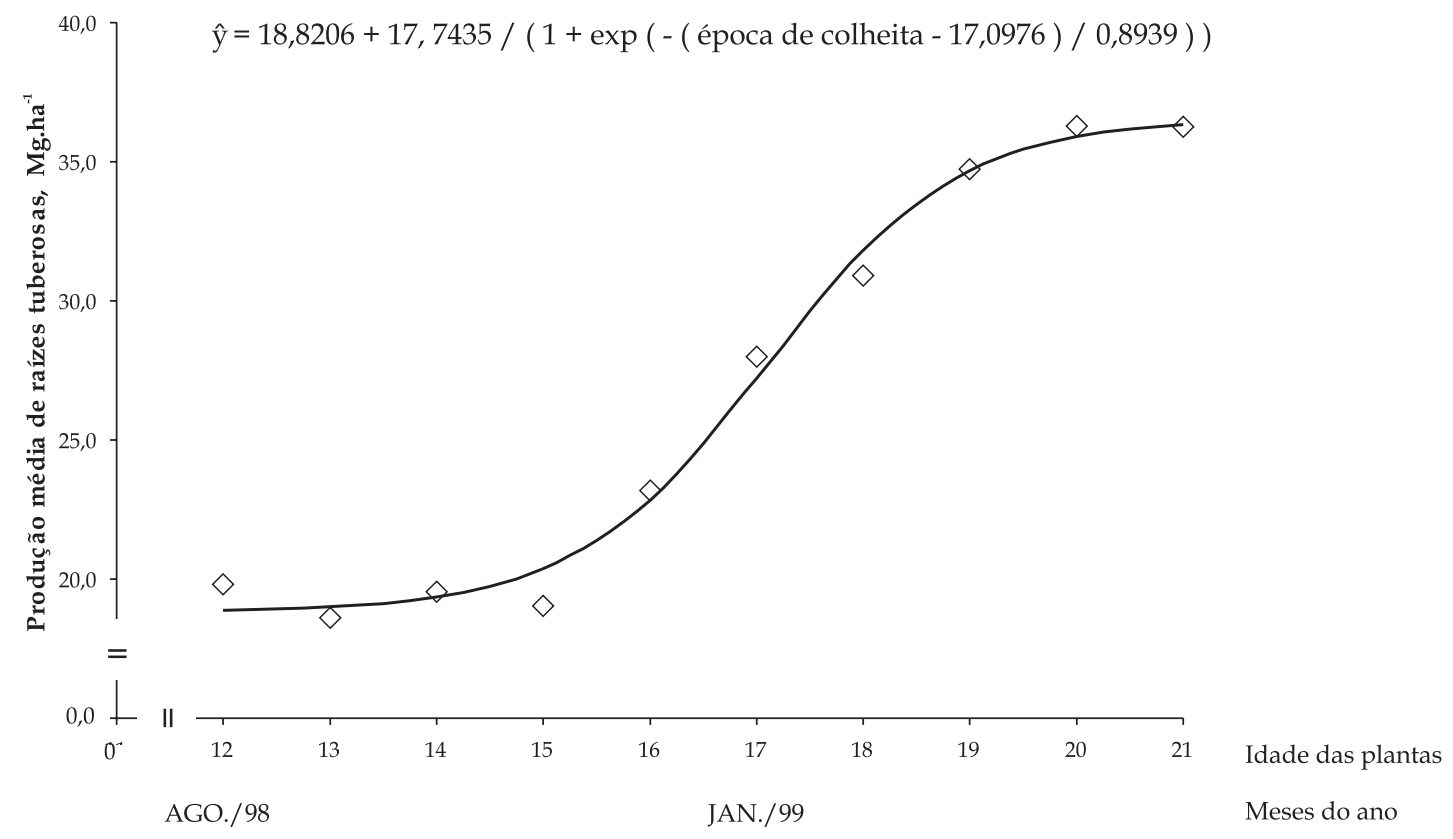

Figura 3. Variação na produção média de raízes tuberosas $\left(\mathrm{Mg}_{\text {.ha }}{ }^{-1}\right)$ de três cultivares de mandioca em dez épocas de colheita, durante o segundo ciclo vegetativo. Araruna (PR), 2001. 


\section{3. Índice de colheita}

O comportamento médio das cultivares nas diferentes épocas de colheita não permitiu o ajuste de um modelo matemático que explicasse satisfatoriamente os fenômenos biológicos que porventura tenham influenciado o índice de colheita (Figura 4). Todavia, numericamente, registraram-se valores relativamente elevados nas três primeiras colheitas; tal período correspondeu ao final da primeira fase de repouso fisiológico e ao início da nova estação de crescimento. Dos 14 aos 16 meses, as plantas sofreram redução dos índices de colheita, provavelmente, devido ao intenso e contínuo aumento da produção da parte aérea total (Figura 2), em detrimento do aumento da produção de raízes tuberosas.

A partir de 16 até os 19 meses após o plantio, houve novo aumento dos índices médios, com posterior estabilização das médias até a última colheita. Esse aumento deve-se à elevação significativa da produção de raízes tuberosas nesse período, ao passo que a porção vegetativa já se encontrava em fase adiantada de formação.

A redução do índice de colheita dos 14 aos 16 meses, em vista da formação da estrutura vegetativa, seguida da elevação dos respectivos valores dos 16 aos 19 meses, em decorrência do aumento pronunciado da produção de raízes tuberosas, é atribuída à influência marcante do clima (Figura 1).
Tal fato permitiu a reestruturação do aparato fotossintético, por meio de valores elevados de temperatura média do ambiente e de precipitação pluvial, com conseqüente aumento da produção de raízes tuberosas.

Os índices observados no início do período das colheitas situaram-se na faixa de $49,0 \%$, ao passo que, ao final desse período, os valores foram superiores a $54,0 \%$, sugerindo que no segundo ciclo vegetativo as plantas de mandioca direcionam os fotoassimilados em maiores proporções para as raízes tuberosas, embora a parte aérea, normalmente, tenha a preferência para receber os carboidratos disponíveis (TAN e CocK, 1979). É razoável inferir, entretanto, que no segundo ciclo vegetativo as raízes tuberosas tenham maior preferência por assimilados à parte aérea, constituindo drenos mais poderosos, pois, nesse período, a estrutura vegetativa (mais especificamente as hastes) já se encontra formada.

Com relação às cultivares (Quadro 2), observa-se que houve comportamento diferenciado para a característica índice de colheita. Verificou-se superioridade da cultivar Mico (54,3\%), que não diferiu, no entanto, da cultivar IAC $13(48,4 \%)$, enquanto 'IAC 14' foi responsável pelas menores médias $(44,9 \%)$. Esses resultados concordam, em parte, com os observados por Vidigal-FiLHO et al. (2000) que, estudando o comportamento de diversas cultivares no primeiro ciclo, durante três anos consecutivos e anteriores a este estudo, observaram

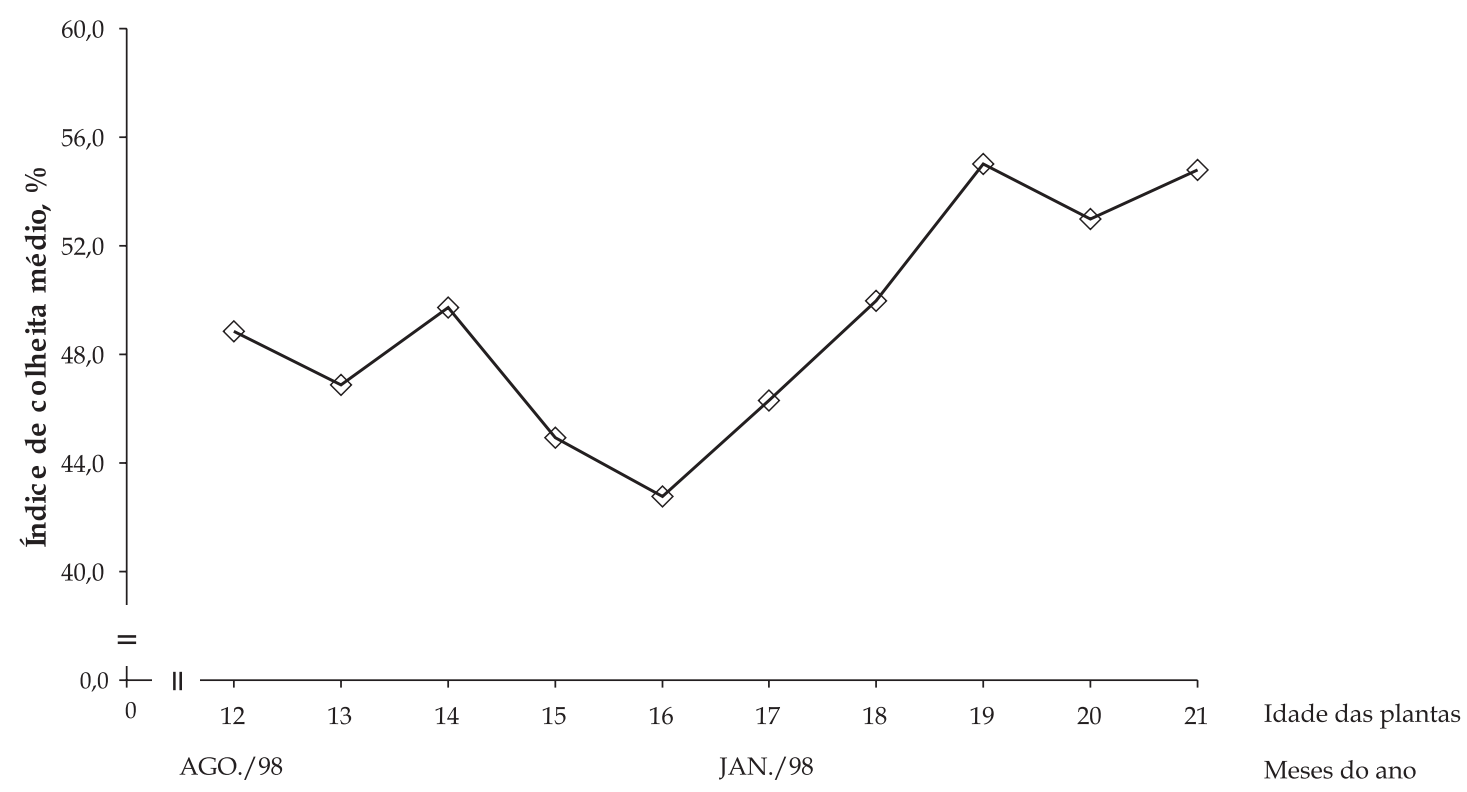

Figura 4. Variação no índice de colheita médio (\%) de três cultivares de mandioca em dez épocas de colheita, durante o segundo ciclo vegetativo. Araruna (PR), 2001. 
Quadro 2. Valores médios referentes às características produção da parte aérea, produção de raízes tuberosas, índice de colheita, produção de massa seca e produção de amido de três cultivares de mandioca em dez épocas de colheita durante o segundo ciclo vegetativo. Araruna (PR), 2001

\begin{tabular}{|c|c|c|c|c|c|}
\hline Cultivares & $\begin{array}{l}\text { Produção } \\
\text { da parte aérea }\end{array}$ & $\begin{array}{l}\text { Produção de } \\
\text { raízes tuberosas }\end{array}$ & $\begin{array}{l}\text { Índice } \\
\text { de colheita }\end{array}$ & $\begin{array}{l}\text { Produção } \\
\text { de massa seca }\end{array}$ & $\begin{array}{l}\text { Produção } \\
\text { de amido }\end{array}$ \\
\hline & t.ha-1 & $\%$ & t.ha-1 & & \\
\hline Mico & $22,89 \mathrm{~b}$ & $28,20 \mathrm{a}$ & $54,30 \mathrm{a}$ & 8,54 a & $5,53 \mathrm{a}$ \\
\hline IAC 13 & $22,84 \mathrm{~b}$ & $26,47 \mathrm{a}$ & $48,43 \mathrm{ab}$ & $9,94 \mathrm{a}$ & $6,05 \mathrm{a}$ \\
\hline IAC 14 & $33,83 \mathrm{a}$ & $25,25 \mathrm{a}$ & $44,93 \mathrm{~b}$ & $9,51 \mathrm{a}$ & 5,99 a \\
\hline$\overline{\mathrm{F}}$ & 17,23 * & $0,97^{\text {ns }}$ & 7,31 * & $1,93^{\text {ns }}$ & $0,63^{\text {ns }}$ \\
\hline
\end{tabular}

*: Significativo ao nível de $5 \%$ pelo teste $\mathrm{F}(\mathrm{P} \leq 0,05)$. ns: Não significativo ao nível de $5 \%$ pelo teste $\mathrm{F}(\mathrm{P}>0,05)$. : Significativo ao nível de 5 pelo teste $\mathrm{F}(\mathrm{P}, 05)$. ns: Não significativo ao nível de $5 \%$ pelo teste $\mathrm{F}(\mathrm{P}>0,05)$. Médias seguidas pela mesma letra, na coluna, não diferem entre si pelo teste de Tukey.

a superioridade de 'Fécula Branca', 'Espeto', 'Verdinha' e 'Fibra' em relação à 'IAC 14' e a 'IAC 13'. A cultivar Mico apresentou também neste trabalho, valores baixos, igualando-se à 'IAC 14' e à 'IAC 13' em alguns casos, contudo superando-os nos demais.

\subsection{Produção de massa seca de raízes tuberosas}

Observa-se que seu comportamento pôde ser explicado mediante o ajuste de uma função polinomial de ordem quadrática (Figura 5). No início das avaliações, a cultura apresentou valores estimados de 6,85 Mg.ha-1, período a partir do qual se observou ligeiro decréscimo da curva até os 13,35 meses (6,57 Mg.ha-1), quando, então, os valores voltaram a aumentar significativamente até os 21 meses, com média de 15,41 Mg.ha-1 ${ }^{-1}$ Tal aumento teve como principal causa, a maior produção de raízes tuberosas (Figura 3), observada no período e, em menor proporção, o aumento dos teores de massa seca nas raízes; ambas as características, muito provavelmente, foram influenciadas pelo clima do período (Figura 1).

Constatou-se aumento de $89,0 \%$ dos valores observados em campo (7,47 Mg.ha ${ }^{-1}$ na primeira e 14,13 Mg.ha-1 na última época de colheita), semelhante ao obtido para a produção de raízes tuberosas. Entretanto, o aumento da produção de massa seca, estimada pela equação ajustada, foi da ordem de $125,0 \%$. Tal diferença de magnitude entre os valores observados e calculados é atribuída ao fato de que os primeiros esboçam tendência de acréscimos decrescentes nas três últimas épocas de colheita (Figura 5). A função quadrática ajustada não permite, nesse período, um ponto de inflexão, sendo, portanto, caracterizada pela tendência de aumento contínuo das médias, o que torna as dimensões finais das médias ajustadas bastante superiores àquelas obtidas em campo.

O aumento obtido pelo ajuste da função foi ainda superior àquele observado por HAMMER et al. (1987), que obtiveram, da primeira para a segunda estação de crescimento, acréscimo de 97,0\%, em média.

Com relação às cultivares (Quadro 2), observa-se que não ocorreram diferenças significativas entre as médias comparadas quanto à produção de massa seca. Esses dados são conflitantes com os obtidos em trabalhos que relatam a existência de diferenças entre cultivares quanto a essa variável. Estudando épocas de colheita de mandioca plantada em diferentes densidades de plantio, no espaçamento 1,0 x 1,0 m, WhOley e BоOTH (1979) encontraram produção de massa seca diferenciada entre as cultivares avaliadas. Da mesma forma, VeltKamp (1985) encontrou diferenças genotípicas para essa característica; tais diferenças se acentuaram a partir de 304 dias após o plantio, aproximadamente aos 10 meses de idade.

\subsection{Produção de amido das raízes tuberosas}

A análise da produção de amido de raízes tuberosas (Figura 6) mostrou que esta característica, a exemplo da produção de massa seca (Figura 5), apresentou comportamento quadrático durante o período avaliado. Observa-se que no período inicial, as médias sofreram ligeiro decréscimo, com o valor mínimo verificado aos 14,30 meses (3,69 Mg.ha-1); a partir desse período, houve aumento significativo das médias até a última colheita, quando se registrou a produção máxima, com valor de $117,5 \%$ superior ao inicial e o estimado, $144,0 \%$ superior ao inicial. 


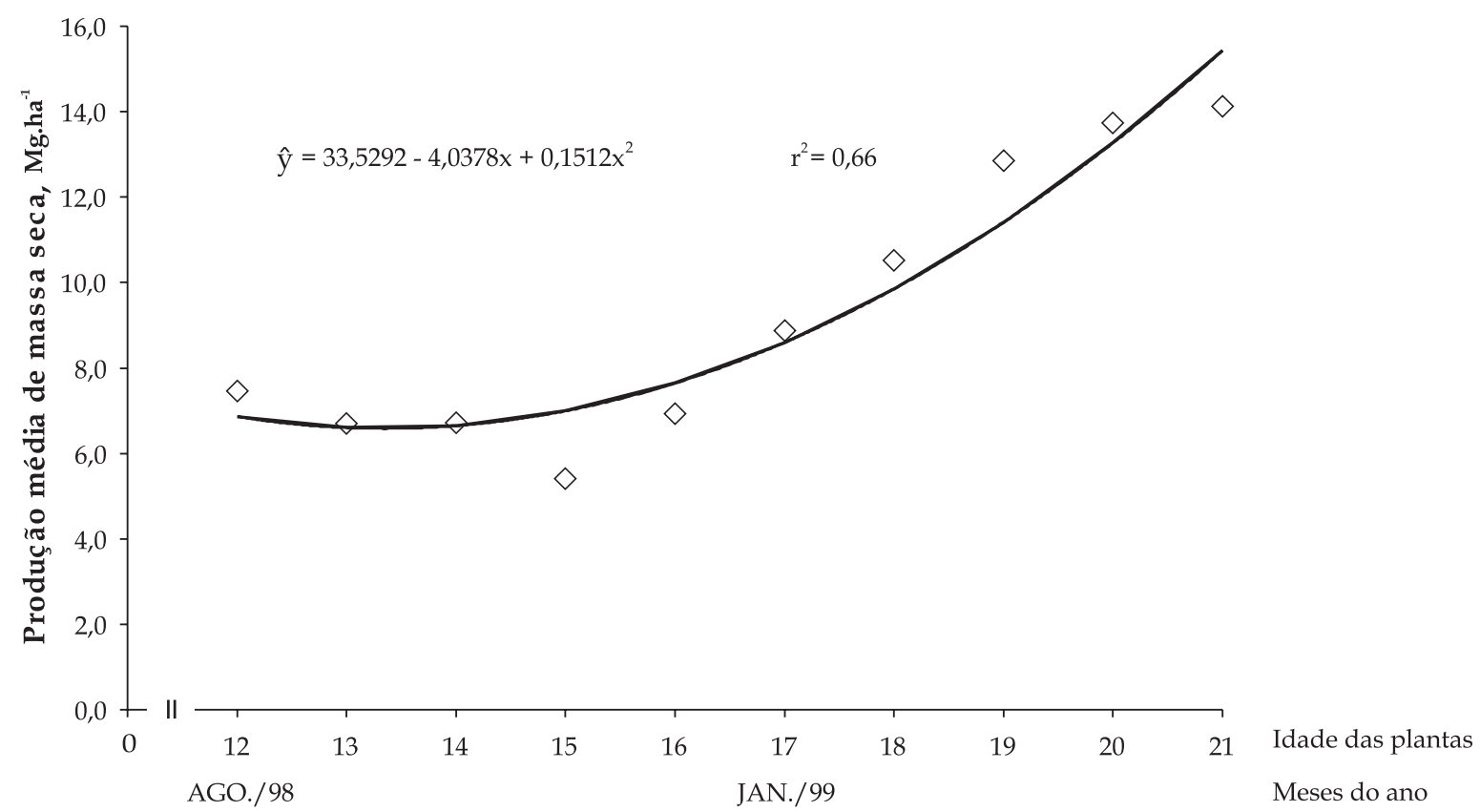

Figura 5. Variação na produção média de massa seca de raízes tuberosas (Mg.ha-1 $)$ de três cultivares de mandioca em dez épocas de colheita, durante o segundo ciclo vegetativo. Araruna (PR), 2001.

Assim como a produção de amido, o teor de amido obtido na massa fresca das raízes tuberosas também se comportou de modo quadrático ao longo das épocas de colheita, apresentando valor elevado por ocasião da primeira (aos 12 meses) que, em média, foi de 236,6 g.kg-1 , decrescendo, a partir desse período, até os 15 meses de idade das plantas, com valor mínimo médio de 161,6 g.kg-1. Daí em diante, os teores de amido voltaram a apresentar incrementos, com novo pico de acúmulo ocorrendo por ocasião da última colheita, aos 21 meses após o plantio, com valor médio de 282,3 g.kg-1 . Portanto, o aumento da produção de amido de raízes tuberosas, ocorrido a partir dos 14,30 meses, foi conseqüência direta do aumento dos teores de amido, associado à elevada produção de raízes tuberosas nesse período (Figura 4).

A elevada produção de amido, assim como os elevados teores de amido presentes na massa fresca das raízes tuberosas aos 21 meses de idade ocorreram por ocasião do início do segundo período de repouso fisiológico das plantas. Nessa época, registraram-se temperaturas mais amenas e baixos índices de precipitação pluvial (Figura 1).

Segundo SRIROTH et al. (1999), nesse período as plantas acumulam maiores teores de amido em suas raízes tuberosas. Esses dados assemelham-se aos de CONCEIÇÃo (1981), que recomenda a colheita da mandioca para uso industrial no segundo ciclo vegetativo, porque tanto a produção de raízes tuberosas quanto a de amido são maiores. De forma análoga, LORENZI e DiAs (1993) afirmam que as produções mais econômicas têm sido aquelas provenientes de culturas de dois ciclos vegetativos, sendo mais adequada a época que coincide com o período de repouso fisiológico das plantas. Resultados semelhantes a este foram ainda obtidos por SARMENTo (1997) que, avaliando o comportamento de quatro cultivares de mandioca, obteve maiores produções de amido aos 20 e 22 meses após o plantio em todas as cultivares avaliadas.

Quanto às cultivares, observa-se que não ocorreram diferenças significativas $(\mathrm{P}>0,05)$ entre as médias comparadas, indicando, dentre as cultivares avaliadas, não haver alguma que se sobressaísse para essa característica (Quadro 2). Comportamento semelhante foi observado por Wholey e Bоотн (1979), quando avaliaram a produção mensal de amido, de cultivares de mandioca em 14 épocas de colheita. Os autores obtiveram diferenças entre as cultivares apenas na primeira colheita, realizada aproximadamente aos 9 meses de idade, ao passo que nas 13 colheitas subseqüentes, a contar da décima época de colheita, as cultivares apresentaram produção de amido estatisticamente semelhante. 


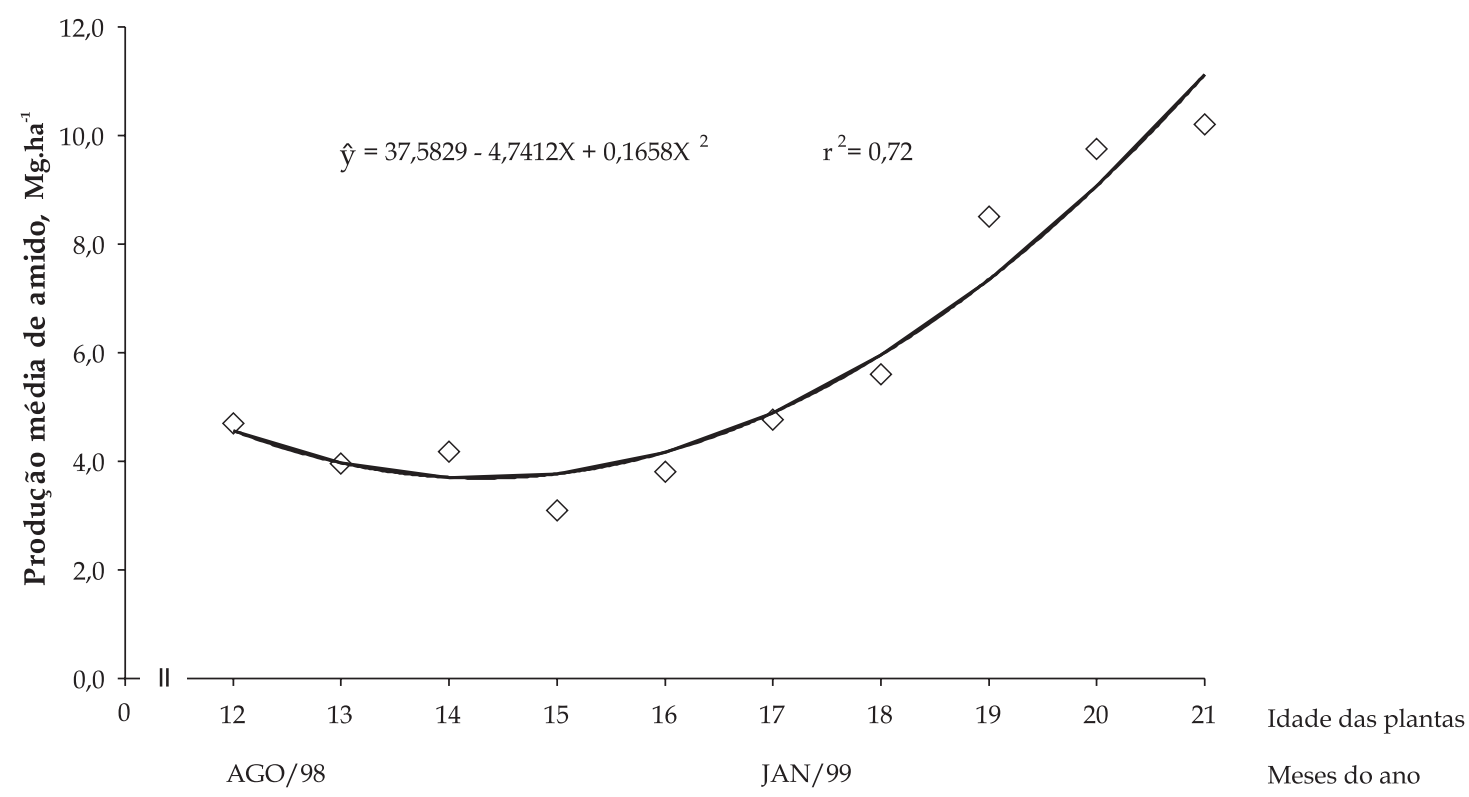

Figura 6. Variação na produção média de amido $\left(\mathrm{Mg}_{\text {.ha }}{ }^{-1}\right)$ de três cultivares de mandioca em dez épocas de colheita, durante o segundo ciclo vegetativo. Araruna (PR), 2001.

\section{CONCLUSÕES}

1. A produção da parte aérea total apresentou, dos 12 aos 21 meses de idade, aumento de 50,0\%.

2. Os maiores índices de colheita ocorreram dos 19 aos 21 meses de idade, com valores em média, superiores a $54,0 \%$.

3. As cultivares não diferiram entre si quanto à produção de raízes tuberosas, de massa seca e de amido.

4. A segunda fase de repouso fisiológico das plantas mostrou-se, para todas as cultivares avaliadas, mais propícia à colheita da mandioca que a primeira fase, em vista da maior produção de raízes tuberosas $(92,5 \%)$, de massa seca $(125,0 \%)$ e de amido $(144,0 \%)$.

\section{AGRADECIMENTOS}

À Pinduca - Indústria Alimentícia Ltda., de Araruna (PR), pelo financiamento do projeto e à Coordenadoria de Aperfeiçoamento de Pessoal de Ensino Superior (CAPES), pela concessão de bolsa de estudo.

\section{REFERÊNCIAS BIBLIOGRÁFICAS}

BANZATTO, D.A.; KRONKA, S.N. Experimentação agrícola. 3.ed. Jaboticabal: FUNEP, 1995. 247p.

CARVALHO, V.D.; CHAGAS, S.J.R.; BOTREL, N. Produtividade e qualidade de raízes em diferentes épocas de colheita de variedades de mandioca. Revista
Brasileira de Mandioca, Cruz das Almas, v.12., n.1/2, p.49-58, 1993.

CASSAVA: a mother crop for millions. Disponível em $h t t p: /$ /www.bath.ac.uk/Admin/topics/topics22/cassava.htm. Acesso em 5 de abril de 2000.

CONCEIÇÃO, A.J. A mandioca. 3.ed. São Paulo: Nobel, 1981. 382p.

CORRÊA, H.; ROCHA, B.V. Manejo da cultura da mandioca. Informe Agropecuário, Belo Horizonte, v.5, n.59/60, p.16-30, 1979.

DINIZ, S.P.S.S. Aspectos fisiológicos e bioquímicos do ácido fusárico, seus efeitos sobre o tecido vegetal, bem como a ação do bálsamo de copaíba no controle da população do Fusarium sp. 1999. 98f. Tese (Doutorado em Bioquímica) Universidade Estadual Paulista, Botucatu.

DORETO, M. Distribuição da cultura da mandioca no Paraná nos anos 80. Londrina: IAPAR, 1993. 19p. (Informe de Pesquisa, 102).

EMBRAPA. Sistema brasileiro de classificação de solo. Rio de Janeiro: CNPS, 1999. 180p.

FUKUDA, W.M.G.; CALDAS, R.C. Influência da época de colheita sobre o comportamento de cultivares e clones de mandioca. Revista Brasileira de Mandioca, Cruz das Almas, v.4, n.2, p.37-44, 1985.

GODOY, H.; CORREIA, A.R.; SANTOS, D. Clima do Paraná: manual agropecuário para o Paraná. Londrina: IAPAR, 1976. p.17-36.

GROXKO, M. Secretaria da Agricultura e do Abastecimento. Departamento de Economia Rural. 
Comparativo de área, produção e produtividade de mandioca (safra 99/00). Disponível em http:// pr.gov.br/seab/. Acesso em 11 de dezembro de 2000.

HAMMER, G.L.; HOBMAN, F.R.; SHEPHERD, R.K. Effects of planting time and harvest age on cassava (Manihot esculenta) in Northern Australia. I. Crop growth and yield in moist environments. Experimental Agriculture, Cambridge, v.23, n.4, p.401-414, 1987.

HOBMAN, F.R.; HAMMER, G.L.; SHEPHERD, R.K. Effects of planting time and harvest age on cassava (Manihot esculenta) in Northern Australia. II. Crop growth and yield in a seasonally-dry environment. Experimental Agriculture, Cambridge, v.23, n.4, p.415424, 1987.

IBGE. Instituto Brasileiro de Geografia e Estatística. Sistema IBGE de recuperação automática. Disponível em http://www.sidra.ibge.gov.br/. Acesso em 11 de dezembro de 2000

KAYODE, G.O. Effects of various planting and harvesting times on the yield, HCN, dry-matter accumulation and starch content of four cassava varieties in a tropical rainforest region. Journal of Agricultural Science, Cambridge, v.101, p.633-636, 1983.

LEONEL-NETO, M. Influência da idade de colheita e espaçamento sobre algumas características de duas cultivares de mandioca (Manihot esculenta, Crantz). 1983. 57f. Dissertação (Mestrado em Fitotecnia) Escola Superior de Agricultura de Lavras.

LORENZI, J.O.; DIAS, C.A.C. Cultura da mandioca. Campinas: Coordenadoria de Assistência Técnica Integral - CATI, 1993. 41p. (Boletim Técnico, 211).

LORENZI, J.O.; PEREIRA, A.S.; MONTEIRO, D.A.; RAMOS, M.T.B. Características agronômicas e culinárias de clones de mandioca. Bragantia, Campinas, v.47, n.2, p.247-253, 1988.

MONTALDO, A. La yuca. San Jose, Costa Rica: IICA, 1979. 386p.
PAULA, J.F. Comportamento de variedades de mandioca (Manihot esculenta, Crantz) em Viçosa, Minas Gerais. 1976. 31f. Dissertação (Mestrado em Fitotecnia) Universidade Federal de Viçosa.

RATKOWSKY, D.A. Handbook of nonlinear regression models. New York: Marcel Dekker, 1990. 241p.

SALES-FILHO, J.B. Distribuição de carboidratos em plantas de mandioca (Manihot esculenta, Crantz) e o efeito do teor de reservas, na brotação e enraizamento de estacas de três posições do caule. 1980. 47f. Dissertação (Mestrado em Fitotecnia) - Universidade Federal de Viçosa.

SARMENTO, S.B.S. Caracterização da fécula de mandioca (Manihot esculenta, Crantz) no período de colheita de cultivares de uso industrial. 1997. 162f. Tese (Doutorado em Ciências Farmacêuticas) - Universidade deSão Paulo.

SRIROTH, K.;SANTISOPASRI, V.; PETCHALANUWAT, C.; KUROTJANAWONG, K.; PIYACHOMKWAN, K.; OATES, C.G. Cassava starch granule structure-function properties: influence of time and conditions at harvest on four cultivars of cassava starch. Carbohydrates Polymers, Amsterdam, v.38, p.161-170, 1999.

TAN, S.L.; COCK, J.H. Branching habit as a yield determinant in cassava. Field Crops Research, Amsterdam, v.2, p. 281-289, 1979.

VELTKAMP, H.J. Physiological causes of yield variation in cassava (Manihot esculenta, Crantz). Wageningen Papers, v.85/86, 1985. 103f. Thesis (Ph.D.) Netherlands, Agricultural University, Wageningen.

VIDIGAL-FILHO, P.S.; PEQUENO, M.G.; SCAPIM, C.A.; GONÇALVES-VIDIGAL, M.C.; MAIA, R.R.; SAGRILO, E.; SIMON, G.A.; LIMA, R.S. Avaliação de cultivares de mandioca na região Noroeste do Paraná. Bragantia, Campinas, v.59, n.1, p.69-75, 2000.

WHOLEY, D.W.; BOOTH, R.H. Influence of variety and planting density on starch accumulation in cassava roots. Journal of the Science, Food and Agriculture, London, v.30, p.165-170, 1979. 